kept on for three days, when he was taken to the operating room and Prof. Dennis applied Malgaigne's hooks. This was done without ether but with considerable pain. These hooks were kept on for six weeks and were then taken out, but not without a great deal of pain during their removal by house surgeọn Riley. He remained in the hospital two weeks more and then left with an ununited fracture, but still with the aid of a cane he was able to crawl around. In October, I 887 , he was brought to me by Dr. G. H. Pierce, of this city. I found that the bone was fractured in three pieces, that there was only cartilaginous union, and that the gap between the fragments was about 2 inches. His trade was that of an awning maker, and at it he could not work at all. In fact, he was liable to fall at any time from the slightest rotation inward or outward of the foot. I advised an operation and he was removed to the Danbury Hospital, where, on November 26, in the presence of Dr. Robt. T. Morris, of New York, Drs. Watson and Pierce, of Danbury, Barber, of Bethel, and Todd, of Ridgefield, I did the following operation: Thoroughly washing the parts with soap and water, aided by a nail brush, and shaving, and then douching the limb with a solution of bichloride $I-I, 000$, I made an incision (an irrigating tube playing on the wound all the time, with a bichloride solution $\mathrm{I}-\mathrm{I}, \mathrm{OOO}$ ), in the median line over the patella. The incision was about 7 inches long and the skin and fascia were then dissected up. I found that the fragments were widely separated and connected only with moderately firm cartilaginous bands. These I dissected out, and with a cartilage knife, I cut away enough of the bone of each fragment to make a well roughened edge. By the aid of assistants I made holes in them and, drawing them together with double silver wire, I twisted them tightly. The coaptation was perfect.

After all the sutures were in position, the ends were twisted and hammered into the larger fragments, where they have remained to this day, causing no inconvenience whatever. The débris was all cleared out, bleeding stopped, the edges of the wound brought together with silkworm gut stitches, iodoform dusted on the external surfaces, a cotton pad placed over all and a roller applied. A straight board splint was applied to the posterior surface of limb, held in place simply with a roller. The patient rallied from the shock quickly, and for ten days did not have a pain or suffer the slightest inconvenience. On the thirteenth day I took off the posterior splint and put on a plaster of Paris dressing, but this caused so much pain that I had to remove it on the same day, replacing it with the old one taken off. The patient was kept in the recumbent position for eight weeks, when he was allowed to go about the ward. The wound healed throughout its entire extent by first intention. There was no in- flammation of any character, and when he was discharged after three months there was firm union; the limb was as strong, he said, as ever. Here certainly was a man restored to usefulness by the wiring of the fragments when several other methods had failed.

\section{THE MECHANICAL TREATMENT OF SYNOVITIS OF THE WRIST.}

BY CHARLES F. STILLMAN, M.Sc., M.D., OF CHICAGO. (MEMBER OF THE AMERICAN ORTHOPADIC

In cases of a mild grade of inflammatory action, felt splints or immobile dressings may be used, but in those of a more serious character, when traction becomes necessary, it may readily be produced, and fixation of the joint increased and maintained by the use of two plain wooden splints extending from the base of the fingers to the elbow (see fig. 2). These are to be notched at each end and are not to be wider than the arm. They are to be placed one anteriorly and the other posteriorly, and are applied by means of adhesive plaster in the following manner:

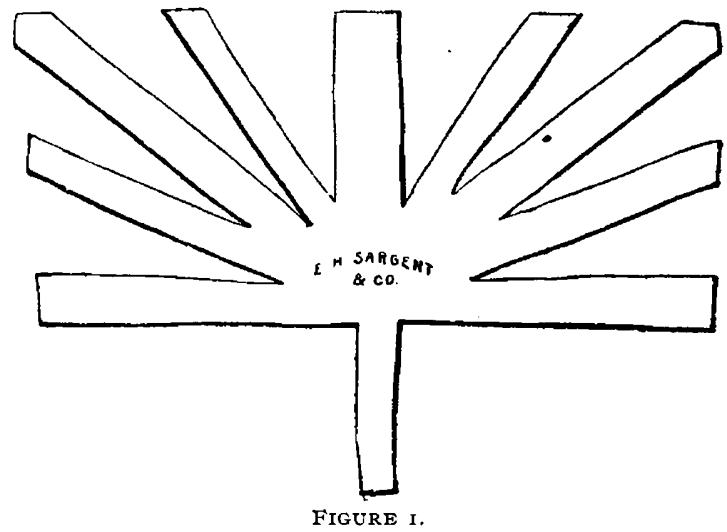

Select plaster of the moleskin variety, and cut four pieces in fan shape shown in fig. 1 . To the center of these attach, with needle and thread, strong webbing straps, each a trifle longer than the wooden splints, and to the free extremities of two of these straps, secure buckles of the same width. These four adhesive plaster fans are next to be interlaced, two above the joint and two below, and the ends are to be drawn over to the extremities of the splints, and buckled together as shown in fig. 2. It will readily be seen that the more tightly these are drawn, the greater the traction will be upon that part of the wrist between the interlacing adhesive plasters, and thus will be effected a true extension of the wrist itself.

These splints are to be secured by four or five transverse bands of adhesive plaster around the arm and hand (see fig. 2), and over all a roller bandage is to be neatly applied. This method 
of producing traction is simple, ready and effect-

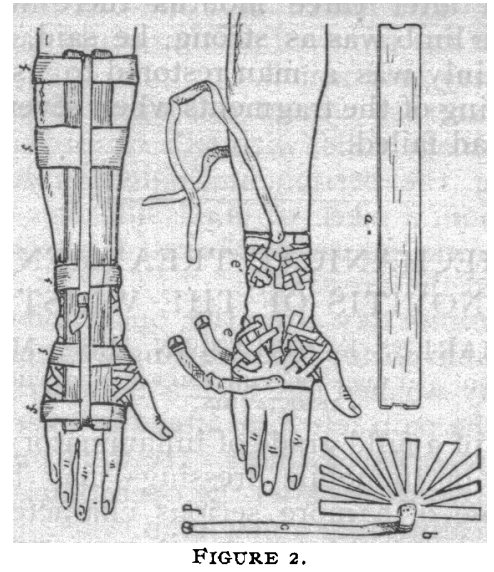

ive for any of the joints, where more elaborate

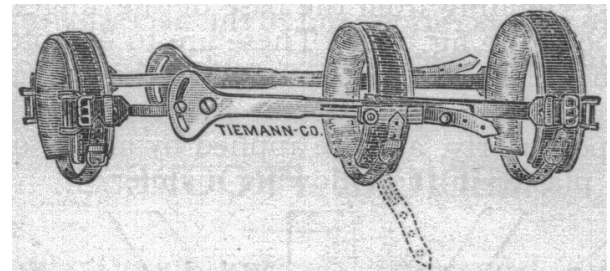

FIG. 3.-Stillman's Brace for Extension of the Wrist.

apparatus carmot be obtained. It is original with

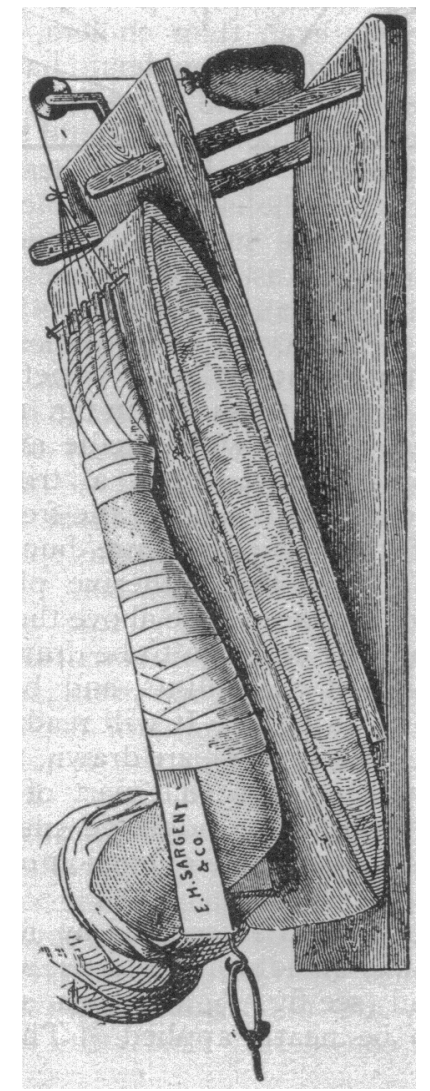

the writer and was first published by him about fight years ago. In many cases it will be found preferable for the surgeon to use a traction splint which will allow the hand to be fixedat any given angle with the arm, and fig. 3 represents such a brace devised by the writer. As will be seen by the engraving it permits fixation at any angle, and allows motion without interfering with the traction upon the wrist, and is applied in a manner similar to that of the wooden splint just described, but as it permits more control of the joint than the latter splint, it is to be be preferred when obtainable.

When extension of the joint is desired-and yet a brace is objected to-Esmarch's traction apparatus may be employed. This is shown in fig. 4 and is applied in a manner corresponding to Buck's extension of the lower limb, the arm resting upon a fillow and inclined plane. But as this method of producing extension, necessarily implies confinement to the couch, it is open to objections, which the use of traction splints, even in severe cases, does not present.

The use of the various forms of apparatus just described renders the treatment of inflammatory and deformative conditions of the wrist an easy matter, and the results of all operations about the joint, are, by their use, rendered very much more certain.

I25 State street, Chicago, I11.

\section{APPENDICITIS, WITH REPORT OF ONE CASE ; ILLUSTRATED.}

BY A. C. LAMOTHE RAMSAY, M.D., OF ST. CLOUD, MINN.

This case is a beautiful illustration of what Senn says in his masterly article on "Ulcerative Appendicitis" (in Vol. xiii, No. I 8 of THE JourNAL): "Many patients suffer from well-defined symptoms indicative of the presence of an inflammatory lesion of the appendix for months and years before it gives rise to a perityphlitis or perforative peritonitis."

Peter R., æt. 27, student, consulted me at my office December $\mathrm{r}_{4}$, for a vague recurring pain in the lower part of the abdomen of four years' duration. $\mathrm{He}$ attributed it to running one day, when he felt something give way in the ilio-cæcal region. He was a strong, muscular young man with a good family history, and besides those pains had never been sick. The pains had never caused vomiting except once, two years ago. His pulse was 82 ; temp. $37.7^{\circ} \mathrm{C}$.

Examination revealed no tympanitis, no swelling in ileo-cæcal region, and only slight tenderness on deep pressure. Rectal examination revealed nothing abnormal. Urine normal. He 